\title{
Identification of Relevant ICF Categories in Vocational Rehabilitation: A Cross Sectional Study Evaluating the Clinical Perspective
}

\author{
Monika E. Finger • Andrea Glässel · Peter Erhart • Felix Gradinger • \\ Andreas Klipstein - Gilles Rivier - Maria Schröer - Christian Wenk • \\ Hans Peter Gmünder • Gerold Stucki • Reuben Escorpizo
}

Published online: 21 April 2011

(C) Springer Science+Business Media, LLC 2011

\begin{abstract}
Introduction Vocational rehabilitation (VR) emphasizes a need for medical support, rehabilitation and biopsychosocial approach to enable individuals to successfully participate in the workforce. Optimal rehabilitation management relies on an in-depth knowledge of the typical spectrum of problems encountered of patients in VR. The International Classification of Functioning, Disability and Health (ICF) is based on a universal conceptual model and provides a holistic view of functioning of the lived experience of people such as those undergoing VR. The objectives of this study are to describe the functioning and health of persons undergoing VR and to identify the most common problems around work and in VR using the ICF as the reference framework. Methods An empirical cross-sectional multicenter study was conducted using convenience sampling from March 2009 to March 2010. Data were collected using a Case Record Form rated by
\end{abstract}

M. E. Finger · A. Glässel · F. Gradinger · G. Stucki ·

R. Escorpizo ( $\square)$

Swiss Paraplegic Research (SPF), Guido A. Zäch Str. 4,

Nottwil 6207, Switzerland

e-mail: reuben.escorpizo@paranet.ch

M. E. Finger · A. Glässel · F. Gradinger · G. Stucki ·

R. Escorpizo

ICF Research Branch in cooperation with the WHO

Collaborating Centre for the Family of International

Classification in Germany (at DIMDI), Nottwil, Switzerland

M. E. Finger · P. Erhart · H. P. Gmünder

Rehaklinik Bellikon, Bellikon, Switzerland

A. Klipstein

Department of Rheumatology and Institute of Physical

Medicine, University Hospital, Zurich, Switzerland health professionals which was based on an extended version of the ICF Checklist containing 292 ICF categories and sociodemographic information. Results 152 patients with various health conditions participated. We identified categories from all four ICF components: 24 for body functions, six for body structures, 45 for activities and participation, and 25 for environmental factors. Conclusions Our study identified a multitude of ICF categories that describe functioning domains and which represent the complexity of VR. Such a comprehensive approach in assessing patients in VR may help to understand and customize the process of VR in the clinical setting and to enhance multidisciplinary communication.

Keywords ICF - Cross-sectional study - ICF-checklist . Vocational rehabilitation

\author{
A. Klipstein \\ Department of Disability Management, Center of Occupational \\ Health AEH, Zurich, Switzerland \\ G. Rivier \\ Centre de Réadaptation Suva, Sion, Switzerland \\ M. Schröer \\ Berufsförderungswerk München, Kirchseeon, Germany \\ C. Wenk \\ Swiss Paraplegic Center, (SPZ), Nottwil, Switzerland \\ G. Stucki - R. Escorpizo \\ Department of Health Sciences and Health Policy, University \\ of Lucerne and SPF, Nottwil, Switzerland
}




\section{Introduction}

Vocational rehabilitation (VR) emphasizes a need for medical support, rehabilitation and biopsychosocial approach to enable individuals to successfully participate in the workforce [1]. VR as a process may also, however, aim to integrate those who have not worked before in order to facilitate work participation.

Optimal rehabilitation management relies on an in-depth knowledge of the typical spectrum of problems encountered in persons in VR. Proper knowledge is needed as a basis to specify rehabilitation goals, selection of interventions and evaluation or re-evaluation of VR outcomes. To facilitate successful VR outcomes, communication between the different stakeholders along the continuum care of VR is essential $[2,3]$. The wide range of health conditions that may affect work participation also poses a challenge to the understanding of VR because the impact of the various conditions may be different. Conditions which possibly require VR can be acquired (e.g. post-motor vehicular accident) or developmental (e.g. cerebral palsy) and may persist up to adulthood. Typical problems in VR have been identified in a number of studies which mostly describe defined patient groups, rehab settings or specific interventions [4], but there also exist numerous settings or interventions that focus on the common goal of reintegrating people into the workforce, without focusing on a specific health condition. Therefore, a common language and understanding that addresses the complexity of VR as a process of integrating the various players and conditions in which VR is necessary, would be of great value.

There are existing work disability and return to work (RTW) models based on different perspectives such as biomedical, psychosocial, ecological or biopsychosocial perspectives [5-9]. There is a need for an overarching conceptual model, that is compatible and complementary to other RTW models and that may help integrate these diverse perspectives in RTW [10, 11].

The International Classification of Functioning, Disability and Health (ICF) [12] by the World Health Organization (WHO) is based on a universal conceptual model and offers a classification system which allows a comprehensive description of health and health-related states. Drawing upon the scope of the ICF, it would be possible to provide a holistic view of functioning or the lived experience of people such as those undergoing VR. The ICF categories that state the domains of body functions $(b)$, body structures (s), activities and participation (d), environmental factors (e), and personal factors (not coded) could facilitate the description and classification of all relevant aspects of functioning and health in individuals, independent of a specific assessment instrument [13]. As a classification system, the ICF provides alphanumeric codes

that are arranged in a hierarchical fashion, hence different levels, for each of the ICF categories or functioning domains. Below is an illustration of this categorization:

ICF component

Chapter

Second-level category

Third-level categories

Thus, the ICF would be particularly helpful in the area of clinical evaluation of patients where different instruments are being used and where a standard list of functioning domains would be beneficial to clinician's planning of interventions and the comparison of data for population health statistics [14-16].

The objectives of this study are to describe the functioning and health of patients undergoing VR and to identify the most common problems around work and in VR using the ICF as the reference framework.

\section{Methods}

\section{Study Design}

An empirical cross-sectional multicenter study [17] was conducted from March 2009 to March 2010 as a part of the preliminary studies in the international project "Development of ICF Core Sets for Vocational Rehabilitation" [18]. This study is one of four studies that investigated the important aspects of functioning in VR from different perspectives. Ethics approval was obtained for each of the study centers. The Declaration of Helsinki was employed in the conduct of the study.

Population

In this study, a convenience sample of 152 patients in VR was gathered from four VR centers in Switzerland and one center in Germany. The following were the inclusion criteria: (1) primary diagnosis (according to the International Classification of Diseases and Health related Disorders ICD-10 [19] that causes functioning problems which required VR. (2) at least 18 years old, (3) can speak, read, and write in German, (4) able to make decision for her- or himself as attested by a health professional, (5) informed of the purpose and reason of the study, and both have been understood, and (6) signed the "patient informed consent form".

Two study centers in Switzerland had a VR setting of work evaluation, ergonomic evaluation, and work-specific physical and cognitive training. In the third center, 
vocational evaluation and return to work interventions were integrated in an early stage of spinal cord injury rehabilitation. In the fourth center, work related vocational training and supported employment for outpatients were offered. The fifth center located in Germany had a VR setting of vocational orientation and vocational training for in- and out-patients. The study centers were chosen to obtain a comprehensive picture of the whole continuum of vocational rehabilitation including the diversity of health conditions and common VR interventions. Health conditions included neurologic conditions such as traumatic brain injuries, stroke and spinal cord injuries, mental diseases like depression or schizophrenia, internal medical diseases such as asthma, or cardiac infarction, and musculoskeletal conditions such as low back pain, fractures of the vertebrae or contusion, distortion, fracture or cut injuries of hands or legs.

\section{Instruments}

Data were collected with a Case Record Form for health professionals (CRF-HP), which was documented and rated by a health professional. Sociodemographic information such as age and sex, main diagnoses, professional and work history, and the current VR intervention were extracted from the medical record. The Extended ICF Checklist [20] was administered during the interview. A pre-test of the feasibility of the CRF-HP was made. The average length of interview in the pretest ranged from 50 to $80 \mathrm{~min}$.

\section{The Extended ICF Checklist}

The basis of the Extended Checklist for VR is the ICF Checklist version 2.1a developed by the World Health Organization (WHO) [21]. It includes a selection of 125 out of 362 existing second level categories, representing the classifiable ICF components: body function (b), body structure ( $s$ ), activities and participation (d), and environmental factors (e). To this checklist, more ICF categories have been added that were considered relevant to VR. This extension was first made through a literature search where common assessment instruments in VR were identified and linked to the ICF based on established inking-rules [22]. 31 second level and 75 third and fourth level categories, which were not covered by the ICF Checklist, were added, hence, "extended". As a second step, the checklist was presented to a group of experts in VR and we asked for categories they believed were missing from the checklist. This second step resulted in the integration of all second level categories from environmental factors and all third level categories from chapter e5 Services, systems and policies. Nine more second level categories and 52 third and forth level categories were added to the checklist.
Hence, the Extended ICF Checklist for VR contained 96 categories from body functions (32.9\%), 19 categories form body structures (6.5\%), 120 categories from activities \& participation $(41.1 \%)$ and 57 environmental factors $(19.5 \%)$.

The presence of a problem was denoted for each category of the components body functions, body structures and activities and participation using a visual analogue scale (VAS) of 1-100 (the higher the number, the higher the magnitude of the problem, impairment, limitation, or restriction). The categories of the component environmental factors were rated as being a facilitator or a barrier. VAS was also used but this time with positive sign denoting as "facilitator" i.e. +1 to +100 , otherwise it was considered "neutral" or "barrier". In addition, other qualifiers were used-" 8 " was used if the available information was not sufficient to rate that ICF category and "9" if the category was not applicable.

The rating of each ICF category was determined by the health professional/interviewer based on his or her interaction with the patient during the interview. This determination was based on the evaluation of the response of the interviewee, observations made by the interviewer during the interview, and consultation of medical records.

\section{Procedure}

The recruitment of the patients was performed by center representatives (CR). The CRs were made aware of the inclusion criteria and were informed about the project. Potential study participants were asked to take part in the study. If patients agreed, their names were forwarded to a study coordinator who then explained the study. Once written informed consent forms were received, a health professional who was trained in administering the study procedures and contents, examined the medical record of the patient and then conducted the interviews. The health professional filled in the CRF-HP. Written material was provided. Plausibility checks were performed by the study coordinator throughout the period of data collection. The data collected were saved in a secure electronic database Microsoft ${ }^{\circledR}$ Access 2007 (Microsoft Corporation, Redmond WA).

\section{Data Analysis}

Descriptive statistics were used to characterize the study population and to examine the frequency of problems recorded in the Extended ICF Checklist. The ICF categories in the components body functions, body structures, and activities \& participation that were rated on the VAS with 5 or more points out of the 100 were arbitrarily regarded as impaired, limited, or restricted. Ratings below 5 were not 
considered for analyses at this time. In the component environmental factor, barriers or facilitators rated below of 5 points out of 100 (meaning neither a facilitator nor a barrier) were also not included in the analyses. Missing values and response options rated as "not applicable" and "not definable" were not considered in the analyses, while co-morbidities were duly noted. The ICF categories that were problematic in at least $20 \%$ (arbitrary cut-off) of the patients were reported. The results for the study population and sub-population based on health condition groups were examined: neurologic condition, mental condition, internal medical condition, musculoskeletal condition concerning the trunk ("MSC_trunk"), musculoskeletal condition concerning the extremities ("MSC_ext"). The results for "MSC_trunk" and "MSC_ext" were presented separately, due to the distinction made in the literature between the two.

Data analyses were performed with SPSS.14.0 for Windows (SPSS Inc., Chicago, IL USA) for the descriptive presentation and to examine relevant second-level categories (aggregated to).

\section{Results}

The sample characteristics of the patients are shown in Table 1. Most of the patients were male $(77.6 \%)$. On average, the work experience was 11 years with range of 0-42 years. More than half of the patients were in VR due to a musculoskeletal condition followed by neurologic and mental conditions. Internal medical conditions as main diagnoses consisted $5.3 \%$ of the study sample. Sixteen and half percentage points of the patients had relevant internal medical co-morbidity conditions.

Tables 2, 3, 4, 5 show the ICF categories which were relevant in at least $20 \%$ of the patients. Percentages are shown for the sample and for the condition subgroups. In the component environmental factors, percentage of barriers and facilitators is shown for each category rated in at least $20 \%$ of the patients as either a barrier or as facilitator.

Overall, there were 90 ICF categories that were identified as relevant. Twenty-four categories came from component body function, 6 from the component body structures, 45 from the component activities and participation, and 25 from environmental factors.

\section{Discussion}

VR is a multidisciplinary and complex process and plays a key role in facilitating or improving work participation. The objective of this study was to describe functioning and health of individuals in VR from the clinical perspective using the ICF. The Extended ICF checklist proved to be a useful instrument to comprehensively capture relevant problems in functioning and environmental barriers and facilitators in different VR settings and health conditions. The breadth of functioning domains in VR is reflected in the categories covering body functions, body structures, activities and participation, and environmental factors. The facilitating role of VR combined with the knowledge of these factors that ought to be addressed in VR can be useful in work disability management.

The population in our study consists of patients with different professions and trades and who have received different VR interventions. The diverse study sample was desired with the assumption that the relevant factors describing VR may apply to all forms of VR. We found specificity of some categories to certain diagnostic groups, especially in the component body structures. There were categories that were directly related to a certain diagnostic group (e.g. Spinal cord and related structures (s120) that is mainly related to neurologic conditions such as spinal cord injuries and musculoskeletal-trunk related diseases such as

Table 1 Characteristics of the study population

\begin{tabular}{|c|c|c|c|c|c|c|c|c|c|c|c|c|}
\hline \multirow[b]{2}{*}{$n$} & \multicolumn{2}{|l|}{ Sample } & \multicolumn{2}{|c|}{$\begin{array}{l}\text { Neurologic } \\
\text { condition }\end{array}$} & \multicolumn{2}{|c|}{$\begin{array}{l}\text { Mental } \\
\text { condition }\end{array}$} & \multicolumn{2}{|c|}{$\begin{array}{l}\text { Internal } \\
\text { condition }\end{array}$} & \multicolumn{2}{|c|}{$\begin{array}{l}\text { Musculoskeletal } \\
\text { condition trunk }\end{array}$} & \multicolumn{2}{|c|}{$\begin{array}{l}\text { Musculoskeletal } \\
\text { condition extremities }\end{array}$} \\
\hline & 152 & & 39 & $25.7 \%$ & 16 & $10.5 \%$ & 8 & $5.3 \%$ & 35 & $23.0 \%$ & 54 & $35.5 \%$ \\
\hline Age (years), mean (SD) & 39.3 & SD 10.75 & 40.33 & SD 11.8 & 37.56 & SD 7.81 & 39.88 & SD 10.99 & 41.11 & SD 10.34 & 37.8 & SD 11.03 \\
\hline Gender Male (\%) & 118 & $(77.6 \%)$ & 31 & $79.5 \%$ & 11 & $68.8 \%$ & 5 & $62.5 \%$ & 26 & 74.3 & 45 & $83.3 \%$ \\
\hline Married (\%) & 54 & $(35.5 \%)$ & 14 & $35.9 \%$ & 1 & $6.3 \%$ & 3 & $37.5 \%$ & 13 & $37.1 \%$ & 23 & $42.6 \%$ \\
\hline $\begin{array}{l}\text { Years of professional } \\
\text { experience Mean (SD) }\end{array}$ & 17.28 & SD 11.17 & 17.68 & SD 12.07 & 12.25 & SD 8.39 & 16.38 & SD 10.71 & 18.65 & SD10.1 & 17.85 & SD11.85 \\
\hline Setting out-patient (\%) & 56 & $36.80 \%$ & 9 & $23.10 \%$ & 5 & $31.30 \%$ & 4 & $50 \%$ & 17 & $48.60 \%$ & 21 & $38.90 \%$ \\
\hline In-patient $(\%)$ & 96 & $63.20 \%$ & 30 & $76.90 \%$ & 11 & $68.80 \%$ & 4 & $50 \%$ & 18 & $51.40 \%$ & 33 & $61.10 \%$ \\
\hline With relevant co-morbidities & 80 & $52.6 \%$ & 26 & $66.7 \%$ & 9 & $56.3 \%$ & 6 & $75.0 \%$ & 24 & $68.6 \%$ & 15 & $27.8 \%$ \\
\hline
\end{tabular}

$S D$ standard deviation 
Table 2 ICF categories of the component body functions rated as an impairment in at least $20 \%$ of participants

\begin{tabular}{|c|c|c|c|c|c|c|c|c|c|c|c|c|c|}
\hline \multicolumn{2}{|c|}{ ICF category } & \multirow{2}{*}{\multicolumn{2}{|c|}{$\begin{array}{l}\text { Sample } \\
152\end{array}$}} & \multirow{2}{*}{\multicolumn{2}{|c|}{$\begin{array}{l}\begin{array}{l}\text { Neurologic } \\
\text { conditions }\end{array} \\
39\end{array}$}} & \multirow{2}{*}{\multicolumn{2}{|c|}{$\frac{\begin{array}{l}\text { Mental } \\
\text { conditions }\end{array}}{16}$}} & \multirow{2}{*}{\multicolumn{2}{|c|}{$\begin{array}{l}\begin{array}{l}\text { Internal } \\
\text { conditions }\end{array} \\
8\end{array}$}} & \multirow{2}{*}{\multicolumn{2}{|c|}{$\begin{array}{l}\begin{array}{l}\text { MSC_trunk } \\
\text { conditions* }\end{array} \\
35\end{array}$}} & \multirow{2}{*}{\multicolumn{2}{|c|}{$\begin{array}{l}\text { MSC_extr. } \\
\text { conditions }\end{array}$}} \\
\hline \multirow{2}{*}{$\begin{array}{l}N \\
\text { Code }\end{array}$} & \multirow[b]{2}{*}{ Title } & & & & & & & & & & & & \\
\hline & & $n$ & $\%$ & $n$ & $\%$ & $n$ & $\%$ & $n$ & $\%$ & $n$ & $\%$ & $n$ & $\%$ \\
\hline \multicolumn{14}{|c|}{ Chapter 1: Mental functions } \\
\hline b126 & Temperament and personality functions & 105 & 69.1 & 32 & 82.1 & 15 & 93.8 & 3 & 37.5 & 22 & 62.9 & 33 & 61.1 \\
\hline b130 & Energy and drive functions & 107 & 70.4 & 31 & 79.5 & 14 & 87.5 & 4 & 50.0 & 25 & 71.4 & 33 & 61.1 \\
\hline b134 & Sleep functions & 86 & 56.6 & 25 & 64.1 & 9 & 56.3 & 2 & 25.0 & 22 & 62.9 & 28 & 51.9 \\
\hline b140 & Attention functions & 83 & 54.6 & 27 & 69.2 & 12 & 75.0 & 4 & 50.0 & 14 & 40.0 & 26 & 48.1 \\
\hline b144 & Memory functions & 45 & 29.6 & 17 & 43.6 & 5 & 31.3 & 2 & 25.0 & 6 & 17.1 & 15 & 27.8 \\
\hline b147 & Psychomotor functions & 75 & 49.3 & 23 & 59.0 & 12 & 75.0 & 3 & 37.0 & 16 & 45.7 & 21 & 38.9 \\
\hline b152 & Emotional functions & 118 & 77.6 & 37 & 94.9 & 14 & 87.5 & 5 & 62.5 & 25 & 71.4 & 37 & 68.5 \\
\hline b156 & Perceptual functions & 64 & 42.1 & 5 & 12.8 & 10 & 62.5 & 2 & 25.0 & 13 & 37.1 & 24 & 44.4 \\
\hline b164 & Higher-level cognitive functions & 58 & 38.2 & 24 & 61.5 & 11 & 68.8 & 2 & 25.0 & 10 & 28.6 & 11 & 20.4 \\
\hline b180 & Experience of self and time functions & 73 & 48.0 & 20 & 51.3 & 8 & 50.0 & 6 & 75.0 & 22 & 62.9 & 17 & 31.5 \\
\hline \multicolumn{14}{|c|}{ Chapter 2: Sensory functions and pain } \\
\hline b210 & Seeing functions & 40 & 26.3 & 14 & 35.9 & 3 & 18.8 & 1 & 12.5 & 8 & 22.9 & 14 & 25.9 \\
\hline b260 & Proprioceptive function & 38 & 25.0 & 12 & 30.8 & 1 & 6.3 & 2 & 25.0 & 11 & 31.4 & 12 & 22.2 \\
\hline b265 & Touch function & 42 & 27.6 & 15 & 38.5 & 1 & 6.3 & 4 & 50.0 & 8 & 22.9 & 14 & 25.9 \\
\hline b270 & Sensory functions related to temperature and other stimuli & 73 & 48.0 & 16 & 41.0 & 3 & 18.8 & 3 & 37.5 & 19 & 54.3 & 29 & 53.7 \\
\hline b280 & Sensation of pain & 130 & 85.5 & 29 & 74.4 & 8 & 50.0 & 4 & 50.0 & 35 & 100 & 53 & 98.1 \\
\hline \multicolumn{14}{|c|}{ Chapter 4: Functions of the cardiovascular, haematological, immunological and respiratory systems } \\
\hline b455 & Exercise tolerance functions & 82 & 53.9 & 31 & 79.5 & 10 & 62.5 & 5 & 62.5 & 20 & 57.1 & 16 & 29.6 \\
\hline \multicolumn{14}{|c|}{ Chapter 5: Functions of the digestive, metabolic and endocrine systems } \\
\hline b530 & Weight maintenance functions & 55 & 36.2 & 8 & 20.5 & 6 & 37.5 & 3 & 37.5 & 12 & 34.3 & 26 & 48.1 \\
\hline \multicolumn{14}{|c|}{ Chapter 7: Neuromusculoskeletal and movement-related functions } \\
\hline b710 & Mobility of joint functions & 109 & 71.7 & 26 & 66.7 & 3 & 18.8 & 4 & 50.0 & 29 & 82.9 & 47 & 87.0 \\
\hline b715 & Stability of joint functions & 66 & 43.4 & 11 & 28.2 & 2 & 12.5 & 2 & 25.0 & 22 & 62.9 & 29 & 53.7 \\
\hline b730 & Muscle power functions & 120 & 78.9 & 35 & 89.7 & 6 & 37.5 & 6 & 75.0 & 32 & 91.4 & 41 & 75.9 \\
\hline b735 & Muscle tone functions & 46 & 30.3 & 16 & 41.0 & 2 & 12.5 & 1 & 12.5 & 15 & 42.9 & 12 & 22.2 \\
\hline b740 & Muscle endurance functions & 110 & 72.4 & 34 & 87.2 & 5 & 31.3 & 5 & 62.5 & 29 & 82.9 & 37 & 68.5 \\
\hline b755 & Involuntary movement reaction functions & 78 & 51.3 & 28 & 71.8 & 0 & 0 & 3 & 37.5 & 21 & 60.0 & 26 & 48.1 \\
\hline b760 & Control of voluntary movement functions & 47 & 30.9 & 17 & 43.6 & 1 & 6.3 & 2 & 25.0 & 12 & 34.5 & 15 & 27.8 \\
\hline
\end{tabular}

* MSC_trunk $=$ Musculoskeletal conditions of the trunk

\# MSC_extr. = Musculoskeletal conditions of the extremities

sciatic pain). There were other categories which were relevant to all diagnostic areas in our sample (e.g. muscle power functions (b730) or muscle endurance functions (b740). We found that patients undergoing VR experience a certain degree of homogeneity with regard to their limitation in functioning independent of their health condition or the VR setting. This finding is consistent with the findings of Holtslag and colleagues which showed that in the long term, functional limitations associated with different health conditions become more and more similar [23, 24].

We found the highest prevalence of relevant problems in the component body functions, chapter 1: mental functions. Categories such as b126 temperament and personality functions and b152 emotional functions point out the burden of distress created by the situation of health-related work absence [25]. The category b130 energy and drive functions and b134 sleep functions highlight that individuals in VR often experience a lot of stress, and prolonged or poor recuperation, while having to deal with an energy consuming situation [26, 27]. In clinical practice, these factors are often neglected [28]. We also found a high prevalence of sensation of pain (b280) (85.5\%) in our population. This is consistent with the literature and hence, addressed in intervention planning [4].

Categories from chapter 2: general tasks and demands in the component activities and participation e.g. carrying out 
Table 3 ICF categories of the component body structures rated as an impairment in at least $20 \%$ of participants

\begin{tabular}{|c|c|c|c|c|c|c|c|c|c|c|c|c|c|}
\hline \multicolumn{2}{|c|}{ ICF category } & \multirow{2}{*}{\multicolumn{2}{|c|}{$\begin{array}{l}\text { Sample } \\
152\end{array}$}} & \multirow{2}{*}{\multicolumn{2}{|c|}{$\begin{array}{l}\begin{array}{l}\text { Neurologic } \\
\text { condition }\end{array} \\
39\end{array}$}} & \multirow{2}{*}{\multicolumn{2}{|c|}{$\begin{array}{l}\begin{array}{l}\text { Mental } \\
\text { condition }\end{array} \\
16\end{array}$}} & \multirow{2}{*}{\multicolumn{2}{|c|}{$\begin{array}{l}\begin{array}{l}\text { Internal } \\
\text { condition }\end{array} \\
8\end{array}$}} & \multirow{2}{*}{\multicolumn{2}{|c|}{$\begin{array}{l}\text { MSC_trunk * } \\
\text { condition } \\
35\end{array}$}} & \multirow{2}{*}{\multicolumn{2}{|c|}{$\begin{array}{l}\text { MSK_extr. * } \\
\text { condition } \\
54\end{array}$}} \\
\hline \multirow{2}{*}{$\begin{array}{l}N \\
\text { Code }\end{array}$} & \multirow[b]{2}{*}{ Title } & & & & & & & & & & & & \\
\hline & & $n$ & $\%$ & $n$ & $\%$ & $n$ & $\%$ & $n$ & $\%$ & $n$ & $\%$ & $n$ & $\%$ \\
\hline \multicolumn{14}{|c|}{ Chapter 1: Structures of the nervous system } \\
\hline s120 & Spinal cord and related structures & 35 & 23.0 & 15 & 38.5 & 1 & 6.3 & 0 & 0 & 14 & 40.0 & 5 & 9.3 \\
\hline \multicolumn{14}{|c|}{ Chapter 7: Structures related to movement } \\
\hline s710 & Structure of head and neck region & 36 & 23.7 & 11 & 28.2 & 2 & 12.5 & 2 & 25.0 & 16 & 45.7 & 5 & 9.3 \\
\hline s720 & Structure of shoulder region & 38 & 25.0 & 11 & 28.2 & 3 & 18.8 & 2 & 25.0 & 8 & 22.9 & 14 & 25.9 \\
\hline s730 & Structure of upper extremity & 45 & 29.6 & 8 & 20.5 & 3 & 18.8 & 3 & 37.5 & 7 & 20.0 & 24 & 44.4 \\
\hline s750 & Structure of lower extremity & 76 & 50.0 & 15 & 38.5 & 4 & 25.0 & 4 & 50.0 & 15 & 42.9 & 38 & 70.4 \\
\hline s760 & Structure of trunk & 56 & 36.8 & 38 & 97.4 & 4 & 25.0 & 2 & 25.0 & 26 & 74.3 & 10 & 18.5 \\
\hline
\end{tabular}

* MSC_trunk $=$ Musculoskeletal condition_trunk *1 MSC_extr. = Musculoskeletal condition_extremities

daily routine (d230) and handling stress (d240) and other psychological demands that we found in our study point out the needs already addressed in chapter 1 of the component body functions, e.g. emotional functions (b152). In chapter 4: mobility, changing basic body position (d410) maintaining a body position (d415), lifting and carrying objects (d430) and the category moving around (d455) seem to cover the most important restrictions concerning movement. These findings seem to validate the items assessed by existing outcome measures, for physical capacity evaluation $[29,30]$. Categories from chapter 8: major life areas provide some insight in a person's work life, as defined in the category $d 850$ remunerative employment. The results (prevalence of 92.8\%) for $d 850$ was not totally unexpected as VR has a major focus on remunerative or gainful employment. Also striking is the number of patients who are also restricted in their leisure activities $-92.8 \%$ of the patients reported problems in the category $d 920$ recreation and leisure. Looking at life areas not directly related to work may help to understand the whole range of limitations from a holistic view and to find resources that can be used to facilitate the return to work process with consideration of the non-work factors. This insight strengthens the need to comprehensively evaluate patients in order to decide the appropriate interventions [31].

In terms of environmental factors, relative frequencies for barriers and facilitators have been reported. Obtaining adequate information about the barriers and facilitators to returning to work can be critical, since these factors can often be addressed by providing simple interventions such as adapting the workplace or work scheduling. In such adaptation, the employer or supervisor play important roles. Modified job duties are reported to be an intermediate step in returning back to work. In some cases, a facilitator can simultaneously be a barrier, e.g. e310 immediate family or e570 social security services, systems and policies. For instance, while workers can get physical help from their family, it is also possible that the same family can prevent them, for fear of re-injury, from doing what the worker wants. The social network as represented in chapter e3: support and relationships could impact VR outcomes positively and negatively [32,33]. Financial and organizational support during VR appeared to be strong facilitators. The support from social security services and providers (e570 social security services, systems and policies) and health care services and providers as (e580 health services, systems and policies), were perceived as facilitators in over $70 \%$ of the patients [34]. In contrast, procedural complexities of the workers' compensation, and health care systems as well as the uncertainty regarding coverage for VR seem to be major barriers [35-38]. To address environmental factors in VR often points to a mediator that can be essential in bringing a worker back to work. For example, appropriate work and supportive workplace-relationships as well as job coaching were identified as encouraging return to work [32, 39, 40].

The existence of co-morbidity is an important consideration in the understanding of our study population, as $52 \%$ suffered from a relevant co-morbidity such as depression, migraine, heart diseases, asthma or musculoskeletal pain in the back, neck or upper extremities [41]. Co-morbidities seem to exacerbate the main health issues and additionally contribute to its impact. Often, persons in VR experience a lot of minor limitations during their working life, which in the end leads to a loss of work ability or decrease in work participation. Co-morbidities not only seem to lower quality 
Table 4 ICF categories of the component activities and participation rated as a limitation or restriction in at least $20 \%$ of participants

\begin{tabular}{|c|c|c|c|c|c|c|c|c|c|c|c|c|c|}
\hline \multicolumn{2}{|c|}{ ICF category } & \multirow{2}{*}{\multicolumn{2}{|c|}{$\begin{array}{l}\text { Sample } \\
152\end{array}$}} & \multirow{2}{*}{\multicolumn{2}{|c|}{$\frac{\begin{array}{l}\text { Neurologic } \\
\text { condition }\end{array}}{39}$}} & \multirow{2}{*}{\multicolumn{2}{|c|}{$\frac{\begin{array}{l}\text { Mental } \\
\text { condition }\end{array}}{16}$}} & \multirow{2}{*}{\multicolumn{2}{|c|}{$\begin{array}{l}\begin{array}{l}\text { Internal } \\
\text { condition }\end{array} \\
8\end{array}$}} & \multirow{2}{*}{\multicolumn{2}{|c|}{$\begin{array}{l}\text { MSC_trunk * } \\
\text { condition } \\
35\end{array}$}} & \multirow{2}{*}{\multicolumn{2}{|c|}{$\begin{array}{l}\text { MSC_extr. * } \\
\text { condition } \\
54\end{array}$}} \\
\hline \multirow{2}{*}{$\begin{array}{l}N \\
\text { Code }\end{array}$} & \multirow[b]{2}{*}{ Title } & & & & & & & & & & & & \\
\hline & & $n$ & $\%$ & $n$ & $\%$ & $n$ & $\%$ & $n$ & $\%$ & $n$ & $\%$ & $n$ & $\%$ \\
\hline \multicolumn{14}{|c|}{ Chapter 1: Learning and applying knowledge } \\
\hline d115 & Listening & 32 & 21.1 & 19 & 48.7 & 4 & 25.0 & 0 & 0 & 3 & 8.6 & 6 & 11.1 \\
\hline d155 & Acquiring skills & 46 & 30.3 & 19 & 48.7 & 6 & 37.5 & 2 & 25.0 & 8 & 22.9 & 11 & 20.4 \\
\hline d160 & Focusing attention & 86 & 56.6 & 31 & 79.5 & 10 & 62.5 & 3 & 37.5 & 16 & 45.7 & 26 & 48.1 \\
\hline d163 & Thinking & 42 & 27.6 & 17 & 43.6 & 9 & 56.3 & 2 & 25.0 & 6 & 17.1 & 8 & 14.8 \\
\hline d175 & Solving problems & 49 & 32.2 & 22 & 56.4 & 8 & 50.0 & 2 & 25.0 & 9 & 25.7 & 8 & 14.8 \\
\hline d177 & Making decisions & 45 & 29.6 & 18 & 46.2 & 5 & 31.3 & 3 & 37.5 & 10 & 28.6 & 9 & 16.7 \\
\hline \multicolumn{14}{|c|}{ Chapter 2: General tasks and demands } \\
\hline $\mathrm{d} 210$ & Undertaking a single task & 52 & 34.2 & 19 & 48.7 & 7 & 43.8 & 3 & 37.5 & 7 & 20.0 & 16 & 29.6 \\
\hline $\mathrm{d} 220$ & Undertaking multiple tasks & 50 & 32.9 & 20 & 51.3 & 5 & 31.3 & 1 & 12.5 & 8 & 22.9 & 16 & 29.6 \\
\hline $\mathrm{d} 230$ & Carrying out daily routine & 98 & 64.5 & 31 & 79.5 & 11 & 68.8 & 4 & 50.0 & 25 & 71.4 & 27 & 50.0 \\
\hline $\mathrm{d} 240$ & Handling stress and other psychological demands & 104 & 68.4 & 31 & 79.5 & 15 & 93.8 & 6 & 75.0 & 23 & 65.7 & 29 & 53.7 \\
\hline \multicolumn{14}{|c|}{ Chapter 4: Mobility } \\
\hline $\mathrm{d} 410$ & Changing basic body position & 113 & 74.3 & 28 & 71.8 & 6 & 37.5 & 4 & 50.0 & 35 & 100 & 40 & 74.1 \\
\hline $\mathrm{d} 415$ & Maintaining a body position & 117 & 77.0 & 31 & 79.5 & 5 & 31.3 & 5 & 62.5 & 35 & 100 & 41 & 75.9 \\
\hline $\mathrm{d} 420$ & Transferring oneself & 35 & 23.0 & 9 & 23.1 & 1 & 6.3 & 2 & 25.5 & 14 & 40.0 & 9 & 16.7 \\
\hline $\mathrm{d} 430$ & Lifting and carrying objects & 129 & 84.9 & 31 & 79.5 & 6 & 37.5 & 6 & 75.0 & 35 & 100 & 51 & 94.4 \\
\hline $\mathrm{d} 435$ & Moving objects with lower extremities & 93 & 61.2 & 22 & 56.4 & 3 & 18.8 & 2 & 25.0 & 29 & 82.9 & 37 & 68.5 \\
\hline $\mathrm{d} 440$ & Fine hand use & 46 & 30.3 & 15 & 38.5 & 4 & 25.0 & 4 & 50.0 & 6 & 17.1 & 17 & 31.5 \\
\hline $\mathrm{d} 445$ & Hand and arm use & 65 & 42.8 & 11 & 28.2 & 1 & 6.3 & 4 & 50.0 & 14 & 40.0 & 35 & 64.8 \\
\hline $\mathrm{d} 450$ & Walking & 109 & 71.7 & 31 & 79.5 & 3 & 18.8 & 5 & 62.5 & 32 & 91.4 & 38 & 70.4 \\
\hline $\mathrm{d} 455$ & Moving around & 124 & 81.6 & 35 & 89.7 & 3 & 18.8 & 6 & 75.0 & 32 & 91.4 & 48 & 88.9 \\
\hline $\mathrm{d} 465$ & Moving around using equipment & 33 & 21.7 & 10 & 25.6 & 0 & 0 & 0 & 0 & 5 & 14.3 & 18 & 33.3 \\
\hline $\mathrm{d} 470$ & Using transportation & 43 & 28.3 & 18 & 46.2 & 5 & 31.3 & 1 & 12.5 & 8 & 22.9 & 12 & 22.2 \\
\hline $\mathrm{d} 475$ & Driving & 83 & 54.6 & 28 & 71.8 & 2 & 12.5 & 4 & 50.0 & 18 & 51.4 & 31 & 57.4 \\
\hline \multicolumn{14}{|c|}{ Chapter 5: Self-care } \\
\hline $\mathrm{d} 510$ & Washing oneself & 33 & 21.7 & 11 & 28.2 & 1 & 6.3 & 0 & 0 & 7 & 20.0 & 14 & 25.9 \\
\hline d540 & Dressing & 35 & 23.0 & 13 & 33.3 & 1 & 6.3 & 0 & 0 & 8 & 77.1 & 13 & 24.1 \\
\hline $\mathrm{d} 570$ & Looking after one's health & 91 & 59.9 & 32 & 82.1 & 11 & 68.8 & 6 & 75.0 & 22 & 62.9 & 20 & 37.0 \\
\hline \multicolumn{14}{|c|}{ Chapter 6: Domestic life } \\
\hline d620 & Acquisition of goods and services & 96 & 63.2 & 28 & 71.8 & 4 & 25.0 & 1 & 12.5 & 28 & 80.0 & 35 & 64.8 \\
\hline d630 & Preparing meals & 59 & 38.8 & 18 & 46.2 & 3 & 18.8 & 1 & 12.5 & 13 & 37.1 & 24 & 44.4 \\
\hline d640 & Doing housework & 90 & 59.2 & 22 & 56.4 & 2 & 12.5 & 5 & 62.5 & 29 & 82.9 & 32 & 59.3 \\
\hline $\mathrm{d} 650$ & Caring for household objects & 105 & 69.1 & 24 & 61.5 & 3 & 18.8 & 6 & 75.0 & 32 & 91.4 & 40 & 74.1 \\
\hline d660 & Assisting others & 81 & 53.3 & 25 & 64.1 & 7 & 43.8 & 4 & 50.0 & 15 & 57.1 & 25 & 46.3 \\
\hline \multicolumn{14}{|c|}{ Chapter 7: Interpersonal interactions and relationships } \\
\hline d710 & Basic interpersonal interactions & 72 & 47.4 & 28 & 71.8 & 11 & 68.8 & 3 & 37.5 & 11 & 31.4 & 19 & 35.2 \\
\hline $\mathrm{d} 720$ & Complex interpersonal interactions & 70 & 46.1 & 26 & 66.7 & 10 & 62.5 & 3 & 37.5 & 8 & 22.9 & 23 & 42.6 \\
\hline d730 & Relating with strangers & 37 & 24.3 & 13 & 33.3 & 6 & 37.5 & 2 & 25.0 & 8 & 22.9 & 8 & 14.8 \\
\hline d740 & Formal relationships & 39 & 25.7 & 14 & 35.9 & 6 & 37.5 & 1 & 12.5 & 6 & 17.1 & 12 & 22.2 \\
\hline $\mathrm{d} 750$ & Informal social relationships & 48 & 31.6 & 16 & 41.0 & 10 & 62.5 & 3 & 37.5 & 6 & 17.1 & 13 & 24.1 \\
\hline d760 & Family relationships & 55 & 36.2 & 14 & 35.9 & 10 & 62.5 & 2 & 25.0 & 14 & 40.0 & 15 & 27.8 \\
\hline d770 & Intimate relationships & 43 & 28.3 & 10 & 25.6 & 10 & 62.5 & 3 & 37.5 & 10 & 28.6 & 10 & 18.5 \\
\hline
\end{tabular}


Table 4 continued

\begin{tabular}{|c|c|c|c|c|c|c|c|c|c|c|c|c|c|}
\hline \multicolumn{2}{|c|}{ ICF category } & \multirow{2}{*}{\multicolumn{2}{|c|}{$\begin{array}{l}\text { Sample } \\
152\end{array}$}} & \multirow{2}{*}{\multicolumn{2}{|c|}{$\frac{\begin{array}{l}\text { Neurologic } \\
\text { condition }\end{array}}{39}$}} & \multirow{2}{*}{\multicolumn{2}{|c|}{$\frac{\begin{array}{l}\text { Mental } \\
\text { condition }\end{array}}{16}$}} & \multirow{2}{*}{\multicolumn{2}{|c|}{$\frac{\begin{array}{l}\text { Internal } \\
\text { condition }\end{array}}{8}$}} & \multirow{2}{*}{\multicolumn{2}{|c|}{$\begin{array}{l}\text { MSC_trunk * } \\
\text { condition }\end{array}$}} & \multirow{2}{*}{\multicolumn{2}{|c|}{$\begin{array}{l}\text { MSC_extr. * } \\
\text { condition }\end{array}$}} \\
\hline \multirow{2}{*}{$\begin{array}{l}N \\
\text { Code }\end{array}$} & \multirow[b]{2}{*}{ Title } & & & & & & & & & & & & \\
\hline & & $n$ & $\%$ & $n$ & $\%$ & $n$ & $\%$ & $n$ & $\%$ & $n$ & $\%$ & $n$ & $\%$ \\
\hline \multicolumn{14}{|c|}{ Chapter 8: Major life areas } \\
\hline $\mathrm{d} 810$ & Informal education & 31 & 20.4 & 13 & 33.3 & 4 & 25.0 & 2 & 25.0 & 4 & 11.4 & 8 & 14.8 \\
\hline $\mathrm{d} 825$ & Vocational training & 33 & 21.7 & 6 & 15.4 & 7 & 43.8 & 2 & 25.0 & 7 & 20.0 & 11 & 20.4 \\
\hline d840 & Apprenticeship (work preparation) & 71 & 46.7 & 19 & 48.7 & 8 & 50.0 & 5 & 62.5 & 15 & 42.9 & 24 & 44.4 \\
\hline d845 & Acquiring, keeping and terminating a job & 119 & 78.3 & 32 & 82.1 & 2 & 12.5 & 8 & 100 & 29 & 82.9 & 36 & 66.7 \\
\hline $\mathrm{d} 850$ & Remunerative employment & 142 & 93.4 & 37 & 94.9 & 1 & 6.3 & 8 & 100 & 30 & 85.7 & 52 & 96.3 \\
\hline d870 & Economic self-sufficiency & 42 & 27.6 & 12 & 30.8 & 4 & 25.0 & 1 & 12.5 & 6 & 17.1 & 19 & 35.2 \\
\hline \multicolumn{14}{|c|}{ Chapter 9: Community, social and civic life } \\
\hline d910 & Community life & 75 & 49.3 & 25 & 64.1 & 9 & 56.3 & 3 & 37.5 & 19 & 54.3 & 19 & 35.2 \\
\hline d920 & Recreation and leisure & 141 & 92.8 & 37 & 94.9 & 12 & 75.0 & 6 & 75.0 & 34 & 97.1 & 52 & 96.3 \\
\hline
\end{tabular}

* MSC_trunk $=$ Musculoskeletal condition_trunk *1 MSC_extr. = Musculoskeletal condition_extremities

Table 5 ICF categories of the component environmental factors rated as a barrier (Ba) or facilitator (Fac) in at least $20 \%$ of participants

\begin{tabular}{|c|c|c|c|c|c|c|c|c|c|c|c|c|}
\hline \multirow{2}{*}{$\begin{array}{l}\text { ICF category } \\
N\end{array}$} & \multicolumn{2}{|c|}{ Sample } & \multicolumn{2}{|c|}{$\begin{array}{l}\text { Neurologic } \\
\text { condition }\end{array}$} & \multicolumn{2}{|c|}{$\begin{array}{l}\text { Mental } \\
\text { condition }\end{array}$} & \multicolumn{2}{|c|}{$\begin{array}{l}\text { Internal } \\
\text { condition }\end{array}$} & \multicolumn{2}{|c|}{$\begin{array}{l}\text { MSC_trunk } \\
* \text { condition }\end{array}$} & \multicolumn{2}{|c|}{$\begin{array}{l}\text { MSC_extr. } \\
* \text { condition }\end{array}$} \\
\hline & 152 & & 39 & & 16 & & 8 & & 35 & & 54 & \\
\hline Code Title & $\begin{array}{l}\mathrm{Ba} \\
\%\end{array}$ & $\begin{array}{l}\mathrm{Fac} \\
\%\end{array}$ & $\begin{array}{l}\mathrm{Ba} \\
\%\end{array}$ & $\begin{array}{l}\mathrm{Fac} \\
\%\end{array}$ & $\begin{array}{l}\mathrm{Ba} \\
\%\end{array}$ & $\begin{array}{l}\mathrm{Fac} \\
\%\end{array}$ & $\begin{array}{l}\mathrm{Ba} \\
\%\end{array}$ & $\begin{array}{l}\mathrm{Fac} \\
\%\end{array}$ & $\begin{array}{l}\mathrm{Ba} \\
\%\end{array}$ & $\begin{array}{l}\mathrm{Fac} \\
\%\end{array}$ & $\begin{array}{l}\mathrm{Ba} \\
\%\end{array}$ & $\begin{array}{l}\mathrm{Fac} \\
\%\end{array}$ \\
\hline
\end{tabular}

Chapter 1: Products and technology

e110 Products or substances for personal consumption

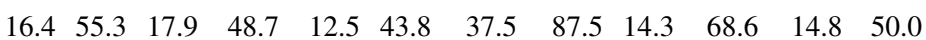

e115 Products and technology for personal use in daily living $\begin{array}{llllllllllll}2.6 & 38.8 & 0 & 41.0 & 6.3 & 25.0 & 100 & 37.5 & 2.9 & 48.6 & 3.7 & 35.2\end{array}$

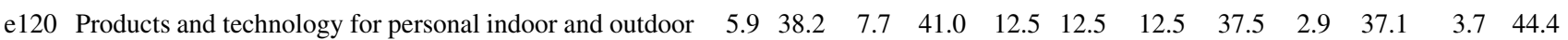
mobility and transportation

e125 Products and technology for communication

$\begin{array}{llllllllllll}0.7 & 34.2 & 2.6 & 56.4 & 0 & 37.5 & 0 & 50.0 & 0 & 20.0 & 1.9 & 24.1\end{array}$

e150 Design, construction and building products and

$\begin{array}{llllllllllll}24.3 & 5.3 & 35.9 & 7.7 & 18.8 & 0 & 0 & 0 & 17.1 & 8.6 & 25.9 & 3.7\end{array}$ technology of buildings for public use

e165 Assets

$\begin{array}{llllllllllll}47.4 & 9.9 & 41.0 & 5.1 & 56.3 & 37.5 & 37.5 & 12.5 & 42.9 & 5.7 & 53.7 & 7.4\end{array}$

Chapter 2: Natural environment and human-made changes to environment

\begin{tabular}{|c|c|c|c|c|c|c|c|c|c|c|c|c|c|}
\hline e220 & Flora and fauna & 34.9 & 7.2 & 33.3 & 5.1 & 6.3 & 12.5 & 25 & 12.5 & 42.9 & 5.7 & 40.7 & 7.4 \\
\hline e225 & Climate & 49.3 & 3.3 & 41.0 & 2.6 & 31.3 & 6.3 & 62.5 & 12.5 & 60.0 & 5.7 & 51.9 & 1.9 \\
\hline $\mathrm{e} 250$ & Sound & 23.7 & 1.3 & 33.3 & 5.1 & 37.5 & 0 & 12.5 & 0 & 25.7 & 2.9 & 13.0 & 0 \\
\hline \multicolumn{14}{|c|}{ Chapter 3: Support and relationships } \\
\hline e 310 & Immediate family & 21.1 & 76.3 & 23.1 & 82.1 & 43.8 & 62.5 & 37.5 & 100 & 14.3 & 85.7 & 14.8 & 66.7 \\
\hline e 320 & Friends & 13.8 & 59.9 & 2.6 & 71.8 & 37.5 & 50.0 & 12.5 & 50.0 & 14.3 & 57.1 & 14.8 & 57.4 \\
\hline e325 & $\begin{array}{l}\text { Acquaintances, peers, colleagues, neighbours and } \\
\text { community members }\end{array}$ & 11.2 & 40.1 & 5.1 & 51.3 & 31.3 & 37.5 & 12.5 & 12.5 & 20.0 & 40.0 & 3.7 & 37.0 \\
\hline e330 & People in positions of authority & 26.3 & 30.3 & 17.9 & 41.0 & 18.8 & 18.8 & 50.0 & 25.0 & 37.1 & 37.1 & 24.1 & 22.2 \\
\hline e355 & Health professionals & 18.4 & 71.7 & 15.4 & 84.6 & 25.0 & 62.5 & 12.5 & 37.5 & 22.9 & 71.4 & 16.7 & 70.4 \\
\hline e360 & Other professionals & 11.2 & 36.2 & 2.6 & 33.3 & 6.3 & 25.0 & 12.5 & 37.5 & 11.4 & 34.3 & 18.5 & 42.6 \\
\hline \multicolumn{14}{|c|}{ Chapter 4: attitudes } \\
\hline e410 & Individual attitudes of immediate family members & 23.0 & 71.7 & 20.5 & 84.6 & 37.5 & 62.5 & 25.0 & 87.5 & 25.7 & 77.1 & 18.5 & 59.3 \\
\hline $\mathrm{e} 420$ & Individual attitudes of friends & 11.2 & 61.8 & 5.1 & 66.7 & 12.5 & 50.0 & 12.5 & 62.5 & 11.4 & 62.9 & 14.8 & 61.1 \\
\hline e450 & Individual attitudes of health professionals & 21.1 & 64.5 & 15.4 & 71.8 & 18.8 & 56.3 & 25.0 & 37.5 & 28.6 & 68.6 & 20.4 & 63.0 \\
\hline
\end{tabular}


Table 5 continued

\begin{tabular}{|c|c|c|c|c|c|c|c|c|c|c|c|c|c|}
\hline \multicolumn{2}{|c|}{ ICF category } & \multicolumn{2}{|c|}{ Sample } & \multicolumn{2}{|c|}{$\begin{array}{l}\text { Neurologic } \\
\text { condition }\end{array}$} & \multicolumn{2}{|c|}{$\begin{array}{l}\text { Mental } \\
\text { condition }\end{array}$} & \multicolumn{2}{|c|}{$\begin{array}{l}\text { Internal } \\
\text { condition }\end{array}$} & \multicolumn{2}{|c|}{$\begin{array}{l}\text { MSC_trunk } \\
* \text { condition }\end{array}$} & \multicolumn{2}{|c|}{$\begin{array}{l}\text { MSC_extr. } \\
* \text { condition }\end{array}$} \\
\hline$N$ & & \multicolumn{2}{|l|}{152} & \multicolumn{2}{|l|}{39} & \multicolumn{2}{|l|}{16} & \multicolumn{2}{|l|}{8} & \multicolumn{2}{|l|}{35} & \multicolumn{2}{|l|}{54} \\
\hline Code & Title & $\begin{array}{l}\mathrm{Ba} \\
\%\end{array}$ & $\begin{array}{l}\mathrm{Fac} \\
\%\end{array}$ & $\begin{array}{l}\mathrm{Ba} \\
\%\end{array}$ & $\begin{array}{l}\mathrm{Fac} \\
\%\end{array}$ & $\begin{array}{l}\mathrm{Ba} \\
\%\end{array}$ & $\begin{array}{l}\mathrm{Fac} \\
\%\end{array}$ & $\begin{array}{l}\mathrm{Ba} \\
\%\end{array}$ & $\begin{array}{l}\mathrm{Fac} \\
\%\end{array}$ & $\begin{array}{l}\mathrm{Ba} \\
\%\end{array}$ & $\begin{array}{l}\mathrm{Fac} \\
\%\end{array}$ & $\begin{array}{l}\mathrm{Ba} \\
\%\end{array}$ & $\begin{array}{l}\mathrm{Fac} \\
\%\end{array}$ \\
\hline $\mathrm{e} 455$ & Individual attitudes of health-related professionals & 10.5 & 28.3 & 2.6 & 20.5 & 12.5 & 25.0 & 0 & 25.0 & 8.6 & 37.1 & 18.5 & 29.6 \\
\hline $\mathrm{e} 460$ & Societal attitudes & 32.9 & 6.6 & 30.8 & 7.7 & 31.3 & 6.3 & 62.5 & 0 & 31.4 & 11.4 & 31.5 & 3.7 \\
\hline \multicolumn{14}{|c|}{ Chapter 5: Services, systems and policies } \\
\hline e540 & Transportation services, systems and policies & 10.5 & 23.7 & 15.4 & 17.9 & 12.5 & 37.5 & 0 & 50.0 & 5.7 & 28.6 & 11.1 & 16.7 \\
\hline e570 & Social security services, systems and policies & 38.8 & 74.3 & 30.8 & 87.2 & 37.5 & 93.8 & 37.5 & 75.0 & 42.9 & 74.3 & 42.6 & 59.3 \\
\hline e580 & Health services, systems and policies & 34.2 & 73.0 & 30.8 & 87.2 & 43.8 & 62.5 & 50.0 & 62.5 & 34.3 & 82.9 & 31.5 & 61.1 \\
\hline e585 & Education and training services, systems and policies & 17.8 & 27.6 & 10.3 & 23.1 & 25.0 & 68.8 & 37.5 & 25.0 & 20.0 & 31.4 & 16.7 & 16.7 \\
\hline e590 & Labour and employment services, systems and policies & 23.6 & 28.3 & 20.5 & 38.5 & 18.8 & 31.3 & 37.5 & 25.0 & 28.6 & 37.1 & 20.4 & 14.8 \\
\hline
\end{tabular}

* MSC_trunk $=$ Musculoskeletal condition_trunk *1 MSC_extr. = Musculoskeletal condition_extremities

of life, they also appear to be a major risk factor for unsuccessful return to work [23, 42].

This cross-sectional study has provided us with broad lists of ICF categories that are relevant to the patients' lived experience and that cover functioning at the individual and societal level. The results of this study could help advance our understanding of factors crucial to successful VR [25]. This study, therefore, provides us with the "what" to look at in the evaluation of individuals in VR from a clinical perspective. An issue remains and that is to determine the use of such set of variables in disability prevention among individuals at risk for work loss due to a health-related issue [43, 44]. Whether or not the ICF categories can provide meaningful information to inform disability prevention strategies is yet to be explored.

When interpreting these results, some issues may be considered. The study results could be biased due to the specific patient selection and convenience sampling employed in our study centers. In current statistics, as shown in the 'Sickness, Disability and Work report 2009' from the Organisation for Economic Co-operation and Development (OECD), approximately one-third of conditions reported were mental and one-third musculoskeletal in nature [45-47]. In our sample, mental conditions represented only $10.5 \%$ of the participants, while the majority of our sample represented musculoskeletal conditions. Therefore, some condition-specific categories might have been missed out. However, the sample we had reflects the "typical" sample of patients in the social systems in Switzerland and Germany [48, 49]. Stratification of job types was not made, hence, it will be difficult to extend our study findings to determine which ICF categories are more meaningful to one type of job versus another job. Another point for consideration is the ICF as a classification system and a taxonomy for health and functioning. It might be prudent to keep in mind the balance of selecting between general definitions of ICF categories (so as to be applicable in various settings and health conditions) and precise definitions (so as to capture the details required by some disciplines). The definition of a single ICF category can be further clarified to define true ICF constructs within that code [50]. Critics have argued that the classification requires further operational definition, if to be useful in practice [11]. Finally, while this study provided a comprehensive list of variables to address VR and functioning, the ICF was not directly linked to concepts like work status, work productivity, work ability, and job type. Therefore, supplementing the ICF with VR-specific indicators such as work status or job type coupled with contextual and personal factors, will further increase the utility of the ICF in clinical practice.

\section{Conclusions}

The ICF, as an overarching conceptual framework and classification system to describe functioning and disability, has been integrated in work-specific and RTW-relevant literature demonstrating compatibility [32, 51, 52]. In this study, we found the ICF to be useful and comprehensive in identifying a set of variables (ICF categories) that describe functioning problems and relevant environmental factors among individuals participating in VR. This set of ICF categories could help in the clinical decision making process of clinicians, and consequently guide appropriate interventions and promote transdisciplinary communication. We encourage clinicians and researchers in VR to further examine the list of variables presented in this study. Further explorative analyses to filter the most significant categories are needed and are being planned in other 
patient populations and VR settings. Another step we encourage is to explore the operationalization of the ICF categories for the purpose of evaluating functioning of the individuals and measuring the relevant factors beyond the traditional biomedical approach. For clinical documentation, the set of ICF categories could serve as the domains to develop a standard profile of functioning for each patient and to identify the barriers and facilitators within the return to work process. To measure and document outcomes of $\mathrm{VR}$ in the practice and in research is required if we want to improve people's lives by increasing their work participation and fulfilling their societal role in general.

Acknowledgments The authors would like to thank Wolfgang Segerer for providing technical consultation, data preparation, and assistance during the conduct of the study. Special thanks to Stéphanie Bessard, Olivier Deriaz, Brigitte Egli, Karl Emmenegger, Jacqueline Huber, Jochen Kunert, Markus Roth, Jana Skoblikova and Christine Treitler who made the data collection in the study centers possible. This project was funded by the Swiss Accident Insurance Company (Suva).

\section{Conflict of interest None.}

\section{References}

1. Selander J. Unemployed sick-leavers and vocational rehabilitation-a person-level study based on a national social insurance material. 1999; PhD thesis, Karolinska Institutet, Department of Rehabilitation Medicine, Stockholm, Sweden.

2. Brunarski D, Shaw L, Doupe L. Moving toward virtual interdisciplinary teams and a multi-stakeholder approach in community-based return-to-work care. Work. 2008;30(3):329-36.

3. Vocational Rehabilitation Task Group-Industrial Injuries Advisory Council, Waddell G, Burton AK, Kendall NA. Vocational rehabilitation-what works, for whom, and when? 1st ed. London: TSO (The Stationery Office); 2008.

4. Buijs PC, Lambeek LC, Koppenrade V, Hooftman WE, Anema JR. Can workers with chronic back pain shift from pain elimination to function restore at work? Qualitative evaluation of an innovative work related multidisciplinary programme. J Back Musculoskelet Rehabil. 2009;22(2):65-73.

5. Schultz IZ, Stowell AW, Feuerstein M, Gatchel RJ. Models of return to work for musculoskeletal disorders. J Occup Rehabil. 2007;17(2):327-52.

6. Solli HM, da Silva AB, Lie RK, Bruusgaard D. Biomedical model of disease and criteria of distributive justice in disability pension cases. Tidsskr Nor Laegeforen. 2005;125(23):3293-6.

7. Cocchiarella L, Turk MA, Andersson G. Improving the evaluation of permanent impairment. JAMA. 2000;283(4):532-3.

8. Cornelius LR, van der Klink JJ, Groothoff JW, Brouwer S. Prognostic factors of long term disability due to mental disorders: a systematic review. J Occup Rehabil. 2010 [Epub ahead of print].

9. Wilkie R, Cifuentes M, Pransky G. Exploring extensions to working life: job lock and predictors of decreasing work function in older workers. Disabil Rehabil. 2010 [Epub ahead of print].

10. Peterson DB. Psychological aspects of functioning, disability, and health. New York: Springer Publishing Company; 2011.
11. Imrie R. Demystifying disability: a review of the International Classification of Functioning, Disability and Health. Sociol Health Illn. 2004;26(3):287-305.

12. World Health Organization. International classification of functioning, disability, and health: ICF. Geneva, Switzerland., 2010.

13. Ustun B, Chatterji S, Kostanjsek N. Comments from WHO for the Journal of Rehabilitation Medicine Special Supplement on ICF core sets. J Rehabil Med. 2004;44(Suppl):7-8.

14. Tempest S, McIntyre A. Using the ICF to clarify team roles and demonstrate clinical reasoning in stroke rehabilitation. Disabil Rehabil. 2006;28(10):663-7.

15. Okawa Y, Ueda S, Shuto K. The utilization of ICF in National Legislation and Policies in Japan. WHO-FIC NETWORK MEETING; 16-22 October.

16. Rentsch HP, Bucher P, Dommen Nyffeler I, Wolf C, Hefti H, Fluri $\mathrm{E}$, et al. The implementation of the 'International Classification of Functioning, Disability and Health' (ICF) in daily practice of neurorehabilitation: an interdisciplinary project at the Kantonsspital of Lucerne, Switzerland. Disabil Rehabil. 2003;25(8):411-21.

17. Grimes DA, Schulz KF. An overview of clinical research: the lay of the land. Lancet. 2002;359(9300):57-61.

18. Escorpizo R, Ekholm J, Gmuender HP, Cieza A, Kostanjsek N, Stucki G. Developing a core set to describe functioning in vocational rehabilitation using the International Classification of Functioning, Disability, and Health (ICF). J Occup Rehabil. 2010;20(4):502-11.

19. World Health Organization. ICD-10: International Statistical Classification of Diseases and Related Health Problems. 10th revision ed. Geneva, Switzerland; 2007.

20. World Health Organization. ICF Checklist. 2003; Available from: http://www.who.int/classifications/icf/training/icfchecklist.pdf. 2010.

21. World Health Organization (WHO). ICF Application and Training Tools. Geneva: World Health Organization 2010 06.01.2010: Available from: http://www.who.int/classifications/icf/icfapptrain ing/en/index.html.

22. Cieza A, Geyh S, Chatterji S, Kostanjsek N, Ustun B, Stucki G. ICF linking rules: an update based on lessons learned. J Rehabil Med. 2005;37(4):212-8.

23. Linder J, Ekholm KS, Jansen G, Lundh G, Ekholm J. Long-term sick leavers with difficulty in resuming work: comparisons between psychiatric-somatic comorbidity and monodiagnosis. Int J Rehabil Res. 2009;32(1):20-35.

24. Holtslag HR, Post MW, van der Werken C, Lindeman E. Return to work after major trauma. Clin Rehabil. 2007;21(4):373-83.

25. Lydell M, Marklund B, Baigi A, Mattsson B, Mansson J. Return or no return-psychosocial factors related to sick leave in persons with musculoskeletal disorders: a prospective cohort study. Disabil Rehabil. 2010 [Epub ahead of print].

26. San L, Ciudad A, Alvarez E, Bobes J, Gilaberte I. Symptomatic remission and social/vocational functioning in outpatients with schizophrenia: prevalence and associations in a cross-sectional study. Eur Psychiatry. 2007;22(8):490-8.

27. Pawlikowska T, Chalder T, Hirsch SR, Wallace P, Wright DJ, Wessely SC. Population based study of fatigue and psychological distress. BMJ. 1994;308(6931):763-6.

28. van der Sluis CK, Eisma WH, Groothoff JW, ten Duis HJ. Longterm physical, psychological and social consequences of severe injuries. Injury. 1998;29(4):281-5.

29. Durand MJ, Brassard B, Hong QN, Lemaire J, Loisel P. Responsiveness of the physical work performance evaluation, a functional capacity evaluation, in patients with low back pain. J Occup Rehabil. 2008;18(1):58-67.

30. Soer R, van der Schans CP, Geertzen JH, Groothoff JW, Brouwer $\mathrm{S}$, Dijkstra PU, et al. Normative values for a functional capacity evaluation. Arch Phys Med Rehabil. 2009;90(10):1785-94. 
31. Kirsh B, Krupa T, Cockburn L, Gewurtz R. A Canadian model of work integration for persons with mental illnesses. Disabil Rehabil. 2010;32(22):1833-46.

32. Young AE. Return to work following disabling occupational injury-facilitators of employment continuation. Scand J Work Environ Health. 2010;36(6):473-83.

33. Brouwer S, Reneman MF, Bultmann U, van der Klink JJ, Groothoff JW. A prospective study of return to work across health conditions: perceived work attitude, self-efficacy and perceived social support. J Occup Rehabil. 2010;20(1):104-12.

34. Gruber EN, Ivezic-Strkalj S, Agius M, Martic-Biocina S. "Since I have my case manager, I am back to life" case management in Croatia. Psychiatr Danub. 2008;20(1):63-70.

35. MacEachen E, Kosny A, Ferrier S. Unexpected barriers in return to work: lessons learned from injured worker peer support groups. Work. 2007;29(2):155-64.

36. Patel S, Greasley K, Watson PJ. Barriers to rehabilitation and return to work for unemployed chronic pain patients: a qualitative study. Eur J Pain. 2007;11(8):831-40.

37. Eriksson UB, Engstrom LG, Starrin B, Janson S. Falling between two stools; how a weak co-operation between the social security and the unemployment agencies obstructs rehabilitation of unemployed sick-listed persons. Disabil Rehabil. 2008;30(8): 569-76.

38. MacEachen E, Kosny A, Ferrier S, Chambers L. The "toxic dose" of system problems: why some injured workers don't return to work as expected. J Occup Rehabil. 2010;20(3):349-66.

39. Macaden AS, Chandler BJ, Chandler C, Berry A. Sustaining employment after vocational rehabilitation in acquired brain injury. Disabil Rehabil. 2010;32(14):1140-7.

40. Lysaght RM, Larmour-Trode S. An exploration of social support as a factor in the return-to-work process. Work. 2008;30(3):255-66.

41. Glozier N, Hackett ML, Parag V, Anderson CS. Auckland Regional Community Stroke (ARCOS) Study Group. The influence of psychiatric morbidity on return to paid work after stroke in younger adults: the Auckland Regional Community Stroke (ARCOS) Study, 2002 to 2003. Stroke. 2008;39(5):1526-32.
42. Zieger M, Luppa M, Meisel HJ, Gunther L, Winkler D, Toussaint $\mathrm{R}$, et al. The impact of psychiatric comorbidity on the return to work in patients undergoing herniated disc surgery. J Occup Rehabil. 2011;21(1):54-65.

43. Krismer M, van Tulder M, The Low Back Pain Group of the Bone, Joint Health Strategies for Europe Project. Strategies for prevention and management of musculoskeletal conditions Low back pain (non-specific). Best Pract Res Clin Rheumatol. 2007;21(1):77-91.

44. Shaw WS, van der Windt DA, Main CJ, Loisel P, Linton SJ. "Decade of the Flags" Working Group. Early patient screening and intervention to address individual-level occupational factors ("blue flags") in back disability. J Occup Rehabil. 2009;19(1):64-80.

45. Patten SB, Williams JV, Wang J. Mental disorders in a population sample with musculoskeletal disorders. BMC Musculoskelet Disord. 2006;7:37.

46. Wang J, Adair CE, Patten SB. Mental health and related disability among workers: a population-based study. Am J Ind Med. 2006;49(7): $514-22$.

47. World Health Organization. The burden of musculoskeletal conditions at the start of the new millenium. 2003; WHO Technical Report Series 919.

48. Fournier-Buchs MF, Gobelet C. Vocational rehabilitation: the swiss model. In: Gobelet C, Franchignoni F, editors. Vocational Rehabilitation. 1st ed. Paris: Springer; 2006. p. 395-403.

49. Schian HM. Vocational Rehabilitation and participation in working life: the Geman model. In: Gobelet C, Franchignoni F, editors. Vocational rehabilitation. 1st ed. Paris: Springer; 2006. p. $309-28$.

50. Maini M. Application problems of the use of the Core set ICF in the rehabilitation area. G Ital Med Lav Ergon. 2008;30(2):178-84.

51. Sandqvist JL, Henriksson CM. Work functioning: a conceptual framework. Work. 2004;23(2):147-57.

52. Wasiak R, Young AE, Roessler RT, McPherson KM, van Poppel MN, Anema JR. Measuring return to work. J Occup Rehabil. 2007; 17(4):766-81. 